\title{
Effects on mammalian cell transcriptome reveal a plant extract's medicinal properties: Potential anti- COVID-19 and anti-cancer properties of Sarcopoterium spinosum
}

\author{
Valid Gahramanov \\ Ariel University \\ Moria $\mathrm{Oz}$ \\ Eastern regional R\&D center \\ Tzemach Aouizerat \\ Hebrew University of Jerusalem \\ Mali Salmon-Divon \\ Ariel University \\ Tovit Rosenzweig \\ Ariel University \\ Jonathan Gorelick \\ Kiryat Arba
}

Elyashiv Drori

Ariel University

Michael Y. Sherman

Ariel University

Bat Chen. R. Lubin ( $\sim$ batchenl@ariel.ac.il)

Ariel University

\section{Research Article}

Keywords: Plant Medicine, RNA sequencing, SARS-COV-2, Autophagy, Signaling Pathway

Posted Date: January 13th, 2022

DOI: https://doi.org/10.21203/rs.3.rs-1250188/v1

License: () (1) This work is licensed under a Creative Commons Attribution 4.0 International License.

Read Full License 
Version of Record: A version of this preprint was published at Plants on August 24th, 2022. See the published version at https://doi.org/10.3390/plants11172195. 


\section{Abstract}

Plants with medicinal properties are usually identified based on traditional medicine knowledge or using low-throughput screens for specific pharmacological activities. Here, we suggest a different approach to uncover a range of pharmacological activities of a chosen plant extract without the need for functional screening. This tactic predicts biological activities of a plant extract based on pathway analysis of transcriptome changes caused by the extract in mammalian cell culture. In this work, we identified transcriptome changes after exposure of cultured cells to an extract of the medicinal plant Sarcopoterium spinosum. Gene Set Enrichment Analysis (GSEA) confirmed known anti-inflammatory and anti-cancer activities of the extract and predicted novel biological effects on oxidative phosphorylation and interferon pathways. Experimental validation of these pathways uncovered strong activation of autophagy, including mitophagy, and astounding protection from SARS-CoV-2 infection. Our study shows that gene expression analysis alone is insufficient for predicting biological effects since some of the changes reflect compensatory effects, and additional biochemical tests provide necessary corrections. In conclusion, this study defines the advantages and limitations of an approach towards predicting the biological and medicinal effects of plant extracts based on transcriptome changes caused by these extracts in mammalian cells.

\section{Introduction}

Understanding physiological effects of medicinal plant extracts is a wide area of biomedical research. ${ }^{1}$ One of the standard approaches towards finding medicinal plant activity is conducting biological screens (Fig. 1). For example, in search for anti-cancer activity, cell lines could be treated with a series of plant extracts, followed by testing in specific screening systems, such as assessment of cell viability. ${ }^{2,3}$ Extracts that cause a significant killing of cancer cells are selected for further evaluation.

The major problem with these kinds of screens is that they depend on a specific test tuned to uncover effects against a specific disease. When such screens are conducted with chemical compounds libraries, hundreds of thousands or millions of compounds are tested in primary screens, which yield a limited number of compounds to be tested in secondary screens. An accepted rate of hits in these primary screens is about $0.1 \%$, i.e., 1 hit per thousand compounds The number of compounds that "survive" secondary screens is orders of magnitude lower. Therefore, for a successful screen, one should have a very high number of initial compounds. With plant extracts, however, it is practically impossible to achieve such numbers. Usually, screens are conducted with tens or hundreds of extracts. Even considering the complexity of extract composition, these numbers are too low to get a reasonably high success rate of the screen, and therefore such screens often fail to yield useful compounds.

In the current study, we proposed an alternative approach towards the identification of novel biological and medicinal activities of plant extracts (Fig. 1). This approach differs from screening in a way that it looks at a range of potential biological activities of an individual extract based on its effects on the cell transcriptome. Accordingly, the cultured cell line is exposed to the extract, and transcriptional changes are 
analyzed, followed by a comprehensive pathway analysis that leads to predicting useful biological activities. Indeed, modern computational methods allow establishing signaling pathways that are affected by treatments with plant extracts ${ }^{4}$, which further allow predicting pathologies that can be treated by the extract. For example, if an extract downregulates the production of inflammatory cytokines, we can predict that such an extract may be able to alleviate an inflammatory disease or cancer. ${ }^{5-7}$ In another example, if an extract downregulates the MAPK pathway, we can predict a potential anti-cancer activity of the extract. ${ }^{8,9}$ Fundamentally, using computational Gene Set Enrichment (GSEA) analysis it is possible to envision biochemical pathways regulated by a chosen plant extract and to predict its potential biological activities. Analysis of dysregulated pathways in such predictions should be treated very carefully since there is a possibility that upregulation of a pathway does not reflect an increase in its activity, but rather its inhibition and compensatory induction of its components to balance the inhibitory effects. Therefore, pathway enrichment analysis must involve such considerations and be accompanied by extensive validation.

To test the hypothesis that the biological and medical effects of the plant extract can be predicted based on cell transcriptome analysis, we chose an extract from the roots of Sarcopoterium spinosum, a Mediterranean traditional plant. Many ethnopharmacological surveys reported the use of S. spinosum extract for the treatment of diabetes treatment ${ }^{10-14}$, cancer therapy ${ }^{13,15}$, and intestinal diseases. ${ }^{12,13}$ Additionally, a positive role of the extract in inflammatory conditions has been investigated. ${ }^{13,14,16,17}$ Therefore, we treated cell lines in culture with extracts from S. spinosum and performed transcriptome analysis to clarify whether we can confirm known therapeutic activities and predict novel biological effects of the plant. Overall, this investigation establishes a novel approach towards finding novel medicinal properties of plants, which is not based on biological screening of a priori selected diseases but rather on an unbiased approach that is based on functional pathway analysis.

\section{Results}

\section{Evaluating the cytotoxicity effect of root extract from Sarcopoterium spinosum}

To test the hypothesis that the transcriptome analysis can be used for predictions of biological activities of plant extracts, we chose Sarcopoterium spinosum (SSE), which has been studied for its anti-diabetic and anti-cancer activities.

To avoid extensive apoptotic signature in the transcriptome analysis, which could mask other important gene expression changes, we first identified subtoxic concentrations and incubation time with the extract. Accordingly, S. spinosum extract was added to a series of cell lines, including A20 mouse lymphoma, HL60 human promyelocytic leukemia, and A549 human lung cancer cells. Cell death was measured by the XTT assay after 24 hours of incubation (Fig. 2). In further experiments, we decided to use the most resistant cell line A549 treated with $200 \mu \mathrm{g} / \mathrm{ml}$ of the extract for 6 hours, thus preceding possible toxicity effects. 


\section{RNAseq and pathway analysis.}

To identify the effects of the extract on the gene expression pattern of A549 cells, RNA was isolated from cells, and RNAseq was performed. A total of 1331 differentially expressed genes (fold change of 2 and FDR<0.05) between treated and non-treated samples were identified. Among these genes, 601 were upregulated and 730 were down-regulated. The overall landscape of gene expression is shown as Volcano Plot in Supplementary Fig. S1 and the list of differentially expressed genes with their expression values is given in Supplementary Table S1. Top differentially expressed genes are visualized by heatmap in Supplementary Fig. S2.

To get an intuition about pathways that are potentially activated or inhibited by the extract we analyzed RNAseq results using protein-protein interactions STRING database (https://string-db.org) (Fig. 3). In addition, GSEA was performed to determine whether pathways predicted from the STRING database are statistically enriched between two biological states (treatment and control). GSEA was employed against the hallmark gene-set signature. Hub genes detected in STRING analysis were found by GSEA to be associated with several critical pathways, including downregulation of WNT/Beta-catenin pathway, TGFbeta signaling, c-Myc signaling, G2/M checkpoint, Spliceosome pathway, and upregulation of Oxidative Phosphorylation and Interferon signaling (Supplementary Table S2 and Fig. S3).

Predicting anti-cancer effects of SSE. Our first question was whether the transcriptome analysis can predict known anti-cancer activities of SSE, and thus focused on pathways relevant to tumor growth and cancer progression. To validate the effects of the extract on cancer-related pathways, inhibition of the WNT/Beta-catenin pathway and TGF-beta signaling was tested by immunoblotting with main intracellular signaling elements anti-phospho- $\beta$-catenin and anti-SMAD2 antibodies, respectively. The phospho- $\beta$-catenin level was reduced upon exposure to extract reflecting its degradation (Fig. 4A). Similarly, the level of SMAD2 was reduced after the administration of the extract (Fig. 4B). Thus, both upstream signaling elements of the pathways and downstream gene expression changes were downregulated upon exposure of cells to the extract. We also validated the effects of the extract on the expression of the centrosome (part of the G2/M pathway) and spliceosome genes by RT-PCR (Fig. 4C).

One of the crucial genes involved in cell cycle progression is c-Myc. Altering the expression of c-Myc is indicative of cell proliferation as well as the progression through the $\mathrm{G} 1$ phase ${ }^{18,19}$. Downregulation of cMyc can lead to $G 1$ arrest, while inhibition of the $G 2 / M$ checkpoint to the $G 2 / M$ arrest ${ }^{20,21}$. Therefore, the prediction based on the pathway analysis was that the extract may cause suppression of both the G1 and G2 phases of the cell cycle. Indeed, FACS analysis of naïve cells and cells treated with the extract indicated depression of S-phase and increase in both G1 and G2/M cell populations (Fig. 5).

Besides WNT/Beta-catenin, TGF-beta, and c-Myc signaling, as well as G2/M checkpoint, downregulation of the spliceosome pathway also suggests an anti-cancer activity, since splicing is significantly affected by cancer transformation ${ }^{22,23}$, and inhibitors of splicing have been developed for cancer treatment ${ }^{24}$. 
Altogether, downregulation of these pathways indicates that previously demonstrated anti-cancer activities of the extract ${ }^{13,14}$ could indeed be predicted from the RNAseq analysis.

Though there is extensive literature on the anti-diabetic activity of SSE, our analysis did not show any indications of such an activity. In other words, we did not observe any transcriptional effects related to the metabolic changes that occurred in diabetes. This lack of effects simply reflects the fact that the antidiabetic activity is unrelated to transcription changes, see Discussion. Therefore, overall, medicinal activities related to effects of and extract on transcriptome can be predicted based on the transcriptome analysis, but transcription-independent effects could be missed.

Previously unknown anti-viral and autophagy-stimulating effects of Sarcopoterium spinosum extract. Among the top highly enriched pathways, we observed strong upregulation of the Interferon pathway and Oxidative Phosphorylation (Supplementary Table S2). Further, we validated the upregulation of a set of interferon- $\gamma$-induced genes and mitochondrial genes in response to incubation with the extract by RT-PCR (Fig. 6A). Strong upregulation of the $y$-interferon pathway predicted that the extract could have anti-viral activities.

To evaluate possible anti-viral effects of $S S E$, we tested whether the extract could protect cells from toxicity caused by SARS-CoV-2 (the virus causing COVID19) infection using a standard approach for testing anti-COVID activities of drugs. VERO E6 or A549-HA-FLAG cells were pretreated with extract for $4 \mathrm{~h}$ followed by a $1 \mathrm{~h}$ exposure to SARS-CoV-2 infection. After $48 \mathrm{~h}$, cell death caused by the viral infection was evaluated using an MTT assay. Figure 6B demonstrates that while viral infection led to the death of 50$60 \%$ of cells, treatment with the extract mitigated this toxicity almost completely. Therefore, an activity of the SSE against a wide spectrum of viruses could be predicted based on the transcriptome analysis and was validated in vitro in a standard test for COVID19 propagation and toxicity.

Since the Oxidative Phosphorylation pathway was upregulated by the extract according to the RNAseq analysis (both nuclear-encoded and mitochondria-encoded genes, see Supplementary Table S1.), we explored the potential use of this information in predicting new medicinal properties of SSE. If the upregulation is associated with higher mitochondrial content and improvement of oxidative phosphorylation, treatment with the extract could be very useful in alleviating diseases associated with the accumulation of defective mitochondria, like neurodegenerative disorders such as Parkinsonism or Friedreich ataxia ${ }^{25-28}$. Accordingly, we sought to test whether treatment with the extract could enhance the production of mitochondria in cells by utilizing a fluorescent probe MitoTracker. A549 cells were treated with the extract for $6 \mathrm{~h}$ and stained with Mitotracker according to the manufacturer's protocol. Images were taken and analyzed using the Hermes Imaging system. Surprisingly, and against the expectations, instead of the higher number of mitochondria in treated cells, we observed a significant and time-dependent decrease in the number of mitochondria (Fig. 7A, B).

Two possible reasons could lead to mitochondrial degradation upon treatment with the extract. The extract could either damage mitochondria and thus make them more susceptible to selective autophagy 
or the extract could cause a genuine activation of the autophagic pathway. To distinguish between these possibilities, we first assessed the membrane potential of mitochondria $(\Delta \Psi)$, since mitochondrial damage usually leads to the collapse of $\Delta \psi^{29}$. To monitor the membrane potential, we used a $\Delta \Psi$ specific JC-1 staining. In healthy cells, JC-1 enters and accumulates in the energized and negatively charged mitochondria and forms red fluorescent J-aggregates. By contrast, upon the collapse of $\Delta \Psi, \mathrm{JC}-1$ also enters mitochondria but to a lesser degree and forms fewer J-aggregates and retains its original green fluorescence. As shown in Figure 8A, incubation with the uncoupler FCCP that causes the collapse of $\Delta \Psi$ leads to the shift of the JC-1 fluorescence from red to green. In contrast, incubation with the extract did not cause such a shift, and mitochondria remained red, indicating healthy $\Delta \Psi$, despite the overall decrease of the mitochondrial content. Therefore, the decrease in the number of mitochondria upon treatment with the extract is not associated with mitochondrial damage.

To test the possibility that the extract over-activates mitochondrial autophagic degradation, we inhibited autophagy by a common blocker of the lysosomal $\mathrm{H}^{+}$-ATPases hydroxychloroquine and measured the number of mitochondria before and after administration of the extract. Indeed, inhibition of autophagy significantly reversed the effect of the extract on the number of mitochondria (Fig. 8B), indicating the autophagy-dependent mitochondrial degradation.

To test if the extract activates the overall autophagic pathway, Western blot analysis of LC3 protein processing was done. Indeed, treatment of A549 cells with the extract led to an increase in LC3B-II levels (Fig. 9B). Furthermore, we observed a decrease in the level of an autophagic receptor p62 that recognizes autophagic targets and recruits them to the autophagic vacuoles (Fig. 9A). Such a decrease is expected upon activation of the autophagic flux due to degradation of $p 62{ }^{30}$. Therefore, treatment of cells with the SSE activates the overall autophagic pathway and facilitates the autophagic degradation of mitochondria and probably other autophagic targets. Such feature of the SSE could be very useful for the treatment of cancer (since autophagic activators have been used for cancer treatment) ${ }^{31}$ and alleviation of various neurodegenerative diseases, associated with defects of mitochondrial degradation, like Parkinsonism ${ }^{32}$.

These two examples with the interferon pathway and oxidative phosphorylation pathway indicate that the RNAseq analysis could be used not only for confirming known activities, but also predicting novel medicinal activities of plant extracts.

\section{Comparative computational pathway analysis of the SSE extract effect on various cell lines.}

A potential problem with the proposed approach is that different cell lines may respond differently to the same plant extract, and therefore, treatment of multiple lines may be needed to obtain a reasonably comprehensive understanding of the potential biological and medicinal effects of the extract. To understand how different transcription responses to the same extract in different cells are, we compared the transcriptome changes in two dramatically different cell types, human lung cancer cells A549 and mouse 3T3 fibroblasts differentiated to adipocytes. As with A549 cells, with the adipocytes, we utilized a pathway analysis software package, including GSEA to establish pathways or biological processes that 
are activated or suppressed (Supplementary Table S3). As shown in Figure 10, the pathways that are either activated or suppressed by the extract treatment are almost the same in both cell lines, even though we could see differences in genes that are enriched in the biological processes (e.g., in the oxidative phosphorylation pathway). These data suggest that regardless of the origin of a cell line one can derive potential biological activities of the chosen extract by using transcriptomic analysis, and therefore there seems to be no need in using multiple cell lines.

\section{Discussion}

Transcriptome analysis has been extensively used to predict biological effects of various biologically active compounds ${ }^{4}$. With plant extracts, however, the situation could be problematic because of the chemical complexity of the extracts, which could contain hundreds of biologically active ingredients. The goal of this research was to get a generalized idea of biological effects of a plant extract through gene set analysis. Such an analysis could hint towards potential medical effects of the plant, which requires linking biological pathways to specific diseases. Prior studies have attempted to analyze effects of certain plant extracts on the transcriptome of target cells or tissues ${ }^{11,13}$, however, predicting biological or pharmacological activities of plant extracts based on these data has not been done.

Since WNT/Beta-catenin pathway, TGF-beta signaling, c-MYC signaling, and G2/M checkpoint are involved in various aspects of cancer development ${ }^{33-36}$, downregulation of all these pathways upon exposure to SSE, can be used to predict anti-cancer properties of the extract. Indeed, downregulation or inhibition of these pathways was shown to suppress cancer development, while their upregulation stimulated cancer ${ }^{37-39}$. Importantly, this RNAseq analysis can significantly enrich our understanding of the mechanism of anticancer activity of the extract. Indeed, previous publications only reported antiproliferative and cytotoxic activities ${ }^{15,40}$. While downregulation of c-MYC and G2/M checkpoint genes explains the antiproliferative activity, downregulation of TGF-beta and WNT/Beta-catenin pathways suggest the suppression of cancer cells stemness and metastasis. In addition to cancer, these pathways are involved in the development of other disorders, as well. TGF-beta signaling is implicated in pathological skin disorders, including excessive scarring and chronic wounds ${ }^{41,42}$. Several reports showed that inhibition of the TGF-beta signaling pathway may be a good strategy for wound healing and reduction of pathological scarring ${ }^{42}$. In other words, identifying signaling pathways affected by an extract may suggest beneficial effects of the extract for the treatment of multiple disorders.

Our distinct finding was strong upregulation of interferons $a$ and $y$ pathways, suggesting that the extract could have anti-viral activities. Indeed, interferons elicit broad anti-viral responses, interfering directly with both viral entry and replication as well as stimulating an immune response through activation of macrophages and NK cells $s^{43-46}$. Both interferon- $a$ and interferon- $\gamma$ were reported to reduce viral titers of SARS-CoV-2 ${ }^{47,48}$, and it is quite plausible that these interferons are involved in SSE's anti-viral activity. There have been studies to use herbs and mushrooms against COVID-19, including several trials with herbal and mushroom mixtures ${ }^{49,50}$. Results of these trials are still under investigation, and there is little 
mechanistic information, including information on the involvement of interferons in effects of these herbs on the propagation of the virus. Moreover, other reports regarding the effect of natural compounds extracted from medicinal plants have shown. Lin et al. (2014) summarized the list of various medicinal plants (Bupleurum spp., Heteromorpha spp., and Scrophularia) that show antiviral activity against human coronaviruses by affecting viral attachment and cell penetration of virus ${ }^{51}$. In addition, several traditional Chinese medicines (TCM) prescriptions such as Pudilan (combination of a four-herb prescription) have been utilized for the SARS-CoV-2 treatment ${ }^{52}$. In this research by using network pharmacology analysis the authors based on the target gene analysis computationally demonstrated possible effects of the extracts on viral penetration and suppression of the cytokine storm caused by COVID-19. However, these predictions have not been validated in wet-lab experiments. To sum up, analysis of natural agents against COVID-19 mostly does not provide sufficient mechanistic information, and further investigation on possible biological pathways related to the disease is required.

A well-known activity of the SSE is the alleviation of Type 2 Diabetes. ${ }^{11,13}$ These effects have been extensively investigated in animal models and cell culture, showing that the extract dramatically enhances insulin signaling. ${ }^{53}$ Still, in our experiment, we could not see any signatures of these effects in the transcriptome analysis, and therefore could not predict these biological and medicinal effects. However, such a lack of predictive ability appears to result from the lack of association of the antidiabetic effects of the extract with transcription changes. Indeed, the extract directly influences insulin signaling. ${ }^{54}$ Its effects on the signaling pathway are seen within minutes of administration, and therefore are transcription-independent. ${ }^{54}$ Thus, our approach towards predicting the biological and medical effects of plant extracts based on the transcriptome analysis has the limitation that it may not be able to uncover transcription-independent effects.

Another important effect was the induction of autophagy. Indeed, treatment with extract led to a decrease in p62 and an increase in LC3 processing, which reflects activation of the autophagic flux ${ }^{55,56}$. Therefore, treatment of cells with the SSE activates the overall autophagic pathway and facilitates the autophagic degradation of mitochondria and probably other autophagic targets, e.g., protein aggregates. Such features of the SSE could be very useful for the treatment of cancer and alleviation of various neurodegenerative diseases, related to defects in mitochondrial degradation, like Parkinsonism.

To our surprise, treatment with the extract, while upregulating mitochondrial genes, reduced the mitochondrial compartment in cells. Therefore, upregulation of the mitochondrial genes seen in the extract-treated cells reflected a compensatory induction of these genes. Accordingly, upon analysis of the RNAseq results, one should be aware that changes in gene expression could reflect compensatory responses, rather than genuine activation of the pathway, and thus validations of the pathway activity are critical.

There have been significant efforts to build databases that integrate information about biological pathways and various diseases to understand the relationships between drugs, genes, and diseases ${ }^{57-59}$. A public database MalaCard could be quite helpful to make predictions about the medicinal properties of 
plant extracts based on the RNAseq analysis ${ }^{60}$. One can input pathways or individual genes, and the database provides a list of diseases associated with this list. A drawback of MalaCard is that it is somewhat unbalanced (https://www.malacards.org/), since it is based on the published articles, and the highest scores usually receive various types of cancer, while other diseases are underrepresented.

High similarities between two entirely different cell lines in pathways affected by SSE suggest that in predicted pharmacological effect of an extract via the transcriptome analysis one can use few or maybe even one cell line. This observation significantly supports the feasibility of our approach. Overall, using this approach will make it feasible to get an idea about the potential medicinal properties of complex plant extracts.

\section{Conclusion}

Here, we tested whether biological and medicinal activities of plant extracts can be predicted based on the effects of an extract on the transcriptome of mammalian cells. Indeed, downregulation of the WNT/ $\beta$ catenin pathway, TGF- $\beta$ signaling, c-MYC signaling, and G2/M checkpoint predicted anti-cancer properties of the SSE extract. Strong upregulation of the interferon-y pathway by SSE suggested that the extract could have anti-viral activities, and indeed we experimentally validated that SSE suppresses the progression of SARS-COV infection. Another important outcome of this search was that SSE can induce autophagy, including autophagic degradation of mitochondria. This activity may be useful for the treatment of major neurodegenerative diseases, as well as cancer. On the other hand, this method misses effects that do not associate with the transcriptome changes. Furthermore, predictions based on the transcriptome data require extensive validation since some transcriptional effects could be compensatory, and do not reflect real effects on medically relevant pathways.

\section{Materials And Methods Plant collection}

Roots of Sarcopoterium spinosum were collected and uprooted from wild-growing plants at the edges of the Ariel University campus in accord with the laws of Israel's authorities for biodiversity.

\section{Aqueous extract}

In addition to the data published in ethnobotanical surveys ${ }^{13,14,61}$, Roots of SSE were washed and boiled for 30 minutes in a ratio of $1 \mathrm{gr}: 10 \mathrm{ml}$ volume of water. After cooling to room temperature, the extract was filtered (Whatman No. 4) and aliquoted.

\section{Cell lines}

The lung carcinoma A549 cell line was grown in DMEM complete medium supplemented with $10 \%$ heatinactivated fetal calf serum and 1\% Penicillin-Streptomycin mixture. A20 mouse lymphoma cells, HL-60 human promyelocytic leukemia cells, NB4 human promyelocytic cells, and K562 chronic myelogenous 
leukemia cell lines were grown in suspension in RPMI supplemented with $10 \%$ heat-inactivated fetal calf serum and 1\% Penicillin-Streptomycin mixture. 3T3-L1 pre-adipocytes were cultured and induced to differentiate. 3T3-L1 adipocytes were used for experiments 14 days after the initiation of differentiation when $80-90 \%$ of cells exhibited adipocyte morphology. Cultures were maintained at $37^{\circ} \mathrm{C}$ in $5 \% \mathrm{CO} 2$.

\section{Cytotoxicity assay}

Cytotoxicity of the plant extracts was determined using the XTT Assay ${ }^{62}$ (Biological Industries, Israel). $1.5 \times 10^{4}$ A549 cells and $8 \times 10^{5}$ cells of A20, HL-60, NB-4, and K562 were seeded in 96-well microplates and allowed to recover. The next day, cells were treated with extract at concentrations ranging from 50 to $600 \mu \mathrm{g} / \mathrm{ml}$, in triplicate for $24 \mathrm{~h}$ incubation. $50 \mu \mathrm{L}$ XTT $(5 \mathrm{mg} / \mathrm{mL})$ was added to each well. After 2 hours of incubation, absorbance was determined using a spectrophotometer at $450 \mathrm{~nm}$. To measure non-specific reading a 630-690nm wavelength was used.

\section{RNA extraction and library construction}

A549 cells were seeded into 6-well plates at a density of $4.5 \times 10^{5}$ cells $/ \mathrm{mL}$. The cells were treated with $200 \mu \mathrm{g} / \mathrm{mL}$ SSE for $6 \mathrm{~h}$. Total RNA was extracted using GENEZOL TRIRNA PURE KIT (Geneaid, Taiwan) according to the manufacturer's protocol. RNA concentration was quantified using Qubit ${ }^{\circ}$ dsDNA HS Assay Kit (Thermo Scientific, Wilmington, DE, USA).

Standard library construction was performed using the TruSeq Stranded mRNA Library Prep kit for Illumina. For each biological replicate, $100 \mathrm{ng}$ of mRNA was used for each library.

\section{RNA sequencing, quality control, sequence alignment, and gene counts}

RNAseq libraries of untreated and treated samples were prepared by using Truseq Stranded mRNA Prep Kit (Illumina) according to manufacture protocol. RNAseq libraries were sequenced by Illumina Hiseq 2500 platform. The generated raw reads underwent quality control checking procedures that included removal of adapter sequences, and low-quality reads. Evaluation of the quality of reads of each sample based on Phred quality score ${ }^{63}$ has been done by using FASTQC ${ }^{64}$ (version 1.1.9, http://www.bioinformatics.babraham.ac.uk/projects/fastqc/) software. Further, obtained high-quality reads were aligned against the human genome (build hg38) using the fast and sensitive alignment program HISAT2 ${ }^{65}$ (http://daehwankimlab.github.io/hisat2/) with default parameters. The number of reads per gene was measured by using featureCounts software ${ }^{66}$ (version 1.22.2).

\section{Normalization and Differential expression analysis}

To make accurate comparisons of gene expression between untreated and treated samples TMM normalization of counts has been done by edgeR R package ${ }^{67}$. Data transformations for RNA-seq differential expression analysis we utilized voom transformation. ${ }^{68}$ Limma package ${ }^{69}$ was used to generate linear models for the detection of differentially expressed genes. Correction for multiple 
comparisons was done using Benjamini-Hochberg $(\mathrm{BH})$ correction method, and genes having an FDR $<0.05$ and fold change $>2$ were considered as differentially expressed. Further, heatmaps of differentially expressed genes were generated by using heatmap function in R programming language using Euclidian as the distance measure and Ward.D2 as the linkage method.

\section{Functional Analysis of RNA-seq (GSEA, STRING)}

Search Tool for the Retrieval Interacting Genes ${ }^{70}$ (STRING) (https://string-db.org) is an online software for analyzing interactions of genes and proteins. Protein-protein interaction (PPI) of the differentially expressed genes were constructed from the STRING database. Constructed interaction patterns were visualized by Cytoscape ${ }^{71}$ (software version 3.8.2). For the construction of PPI networks, active interaction sources, including text mining, experiments, databases, and co-expression as well as species limited to "Homo sapiens" and an interaction score $>0.4$ were applied.

The entire list of genes was ranked according to fold change and used as input to Gene Set Enrichment Analysis $^{72}$ (GSEA). GSEA was employed against the hallmark gene-set signature. The hallmark gene sets were obtained from the Molecular Signature Database v7.2. (http://www.gsea$\mathrm{msigdb.org/gsea/msigdb/index.jsp)} \mathrm{was} \mathrm{used} \mathrm{in} \mathrm{the} \mathrm{analysis.} \mathrm{We} \mathrm{have} \mathrm{taken} \mathrm{into} \mathrm{consideration} \mathrm{gene}$ sets with a P-value $<0.05$ and FDR cutoff of $25 \%$ which is appropriate in GSEA analysis due to the relatively small number of gene sets being analyzed (50). ${ }^{72}$

\section{Cell cycle analysis}

A549 cells were seeded into 24 -well plates at a density of $1 \times 10^{5}$ cells $/ \mathrm{mL}$. The cells were treated with $200 \mathrm{ug} / \mathrm{ml}$ of the extract for $24 \mathrm{~h}$. The cells were harvested using $0.1 \%$ trypsin-EDTA. Cells were then fixed and stained using a propidium iodide flow cytometry kit (Abcam,) according to the manufacturer's protocol. DNA content of the cells was analyzed using a flow cytometer with a Becton Dickson FACS Calibur cell analyzer.

\section{cDNA synthesis}

The complementary DNA (cDNA) was synthesized using 50ng/ $\mu \mathrm{L}$ RNA of each sample. The reverse transcription (RT) reaction was performed according to high capacity cDNA reverse transcription kit instructions (AppliedBiosystems, Inc.).

\section{Real-time PCR}

cDNA was analyzed with real-time polymerase chain reaction (PCR) using the Sequence Detection System (ABIPrism7900; AppliedBiosystems, Inc.FosterCity, CA, USA). cDNA input levels were normalized against human beta-actin (ACTB). Reactions were performed in a $12 \mu \mathrm{L}$ volume containing $4 \mu \mathrm{L}$ cDNA, $0.3 \mu \mathrm{L}$ each of forward and reverse primers, $6 \mu \mathrm{l}$ buffer included in the MasterMix and $1.4 \mu \mathrm{l}$ of DNAse/RNase free water (SYBRRGreenl; AppliedBiosystems, Inc.). PCR cycling conditions were as follows: initial denaturation at $50^{\circ} \mathrm{C}$ for $2 \mathrm{~min}$; followed by denaturation at $95^{\circ} \mathrm{C}$ for $2 \mathrm{~min}$; followed by 40 cycles of denaturation at $95^{\circ} \mathrm{C}$ for $15 \mathrm{~s}$; and annealing and extension at $60^{\circ} \mathrm{C}$ for $1 \mathrm{~min}$. Triplicate was 
performed for each gene to minimize individual tube variability, and an average was taken for each sample.

The results were quantified by a comparative Ct method, also known as the $2 \Delta \mathrm{Ct}$ method (Giulietti et al.,2001.

\begin{tabular}{|l|lll|}
\hline Gene symbols & forward & reverse \\
\hline IFIT2 & gacacggttaaagtgtggagg & tccagacggtagcttgctatt \\
\hline IFIT1 & tgagatgtcactttacatggg & tgtattcccacactgtatttgg \\
\hline CCP110 & agacgcagtctgagaggtagt & cagtgtttgcctgtcaactgg \\
\hline CEP152 & ggagtggcagtctaagctgg & tcactggtggttacttggtca \\
\hline NDUFB11 & cgtccgctgggaatctagc & acggggtccttgtcataacca \\
\hline COX5B & tgtgaagaggacaataccagcg & ccagcttgtaatgggctccac \\
\hline COX6B1 & ctacaagaccgcccctttga & tttagcggtcattgccttctg \\
\hline SRSF11 & caggtgactaatgtctccccg & gcagttcgtcgatcttgcct \\
\hline PNN & gaatgacgtgaggcccatcca & ctctgtttggctgggggtcct \\
\cline { 2 - 4 } & Of anti-Viral activity &
\end{tabular}

Cell lines VERO E6 (ATCC $®$ CRL-1586) and Human Lung Carcinoma Cells (A549) Expressing Human Angiotensin-Converting Enzyme 2 (HA-FLAG) (NR-53522) as well as SARS-CoV-2 (Isolate USA-WA1/2020) were obtained from BEI Resources. All experiments were carried out in a Biosafety level 3 laboratory and conducted under appropriate conditions. Vero E6 cells were cultured in Minimum Essential Media (MEM) supplemented with $2 \%$ fetal bovine serum, penicillin /streptomycin $(100 \mu \mathrm{g} / \mathrm{mL})$, and L-glutamine (2 mM). A549 cells were cultured in Dulbecco's Modified Eagles Medium (DMEM) supplemented with 10\% Fetal Bovine Serum, $2 \mathrm{mM} \mathrm{L-Glutamine,} \mathrm{and} 1 \mu \mathrm{g} / \mathrm{ml}$ puromycin. All cells were cultured at $37^{\circ} \mathrm{C}$ under $5 \%$ $\mathrm{CO} 2$.

Cells were seeded in 96-well flat-bottom microplates at $5^{\star} 10^{4}$ cells $/ \mathrm{ml}$ and incubated overnight to reach sub-confluence. On the next day, cells were pretreated with S. spinosum extract $(100 \mathrm{ug} / \mathrm{ml})$ for $4 \mathrm{~h}$ followed by infection with SARS-CoV-2 at various multiplicities of infections (MOI). After $48 \mathrm{~h}$, viralinduced cytotoxicity was evaluated using MTT (Invitrogen) based on the manufacturer's protocol.

\section{Analysis of Mitochondrial Activity}

A549 cells were seeded into 96 well clear bottom black plates at a density of $12 \times 10^{5}$ cells $/ \mathrm{mL}$. The cells were treated with $200 \mu \mathrm{g} / \mathrm{mL}$ extract for $6 \mathrm{~h}$. After incubation, the cells were stained with MitoTracker Red (Invitrogen) according to the manufacturer's instructions. Representative images were obtained via WiScan ${ }^{\circledR}$ Hermes High Content Imaging System (IDEA Bio-Medical LTD, Rehovot, Israel) at room 
temperature using 20x objective. The data obtained from the microscope were analyzed with Athena software.

\section{Analysis of Mitochondrial Membrane Potential $(\Delta \Psi \mathrm{m})$}

A549 cells were seeded as previously described. The cells were treated with $200 \mu \mathrm{g} / \mathrm{mL}$ extract for $6 \mathrm{~h}$ and stained with JC-1 (Abcam), according to the manufacturer's instructions. Representative images were obtained under a Zeiss confocal microscope equipped with a laser diode $488 \mathrm{~nm}$ and $555 \mathrm{~nm}$.

\section{Autophagy study}

A549 cells were seeded into 96 well black plates and clear bottom at a density of $12 \times 10^{5}$ cells $/ \mathrm{mL}$ and then incubated with $60 \mu \mathrm{M}$ hydroxychloroquine (Sigma-Aldrich) and $200 \mu \mathrm{g} / \mathrm{mL}$ extract simultaneously or extract only for $6 \mathrm{~h}$. Cells were stained with JC-1, according to the manufacturer's instructions. Absorbance in the wells was measured at $530 \mathrm{~nm}$ and $590 \mathrm{~nm}$. All experiments were performed in triplicate on three separate occasions. Data are presented as mean \pm S.D

\section{Western Blot Analysis}

A549 cells in 35mm or $60 \mathrm{~mm}$ dish were lysed with lysis buffer: $40 \mathrm{mM} \mathrm{HEPES,} \mathrm{pH} \mathrm{7.5;} 50 \mathrm{mM} \mathrm{KCl;} 1 \%$ Triton X-100; 2 mM dithiothreitol; 1 mM Na3V04; 50 mM ß-glycerophosphate; 50 mM NaF; 5 mM EDTA; 5 mM EGTA; and supplemented with Proteasome inhibitor Cocktail (Sigma) and PMSF before use. Samples were adjusted to have an equal concentration of total protein and subjected to PAAG electrophoresis followed by immunoblotting. Primary antibodies were purchased from Cell Signaling Technology. Secondary antibodies were purchased from Jackson Immuno Research.

\section{Statistical Analysis}

Statistical analysis was performed on the R programming language. Data are expressed as mean \pm SD. Student's t-test and two-way analysis of variance (ANOVA) were used to evaluate the statistical significance of the difference in two or more groups, respectively. A P-value less than 0.05 was considered significant.

\section{References}

1. Jung, K., Kim, I.-H. \& Han, D. Effect of medicinal plant extracts on forced swimming capacity in mice. Journal of Ethnopharmacology 93, 75-81 (2004).

2. Solowey, E. et al. Evaluating Medicinal Plants for Anticancer Activity. The Scientific World Journal 2014, e721402 (2014).

3. Kauroo, S. et al. Extracts of select endemic plants from the Republic of Mauritius exhibiting anticancer and immunomodulatory properties. Sci Rep 11, 4272 (2021). 
4. Yang, X. et al. High-Throughput Transcriptome Profiling in Drug and Biomarker Discovery. Frontiers in Genetics 11, 19 (2020).

5. Landskron, G., De la Fuente, M., Thuwajit, P., Thuwajit, C. \& Hermoso, M. A. Chronic Inflammation and Cytokines in the Tumor Microenvironment. J Immunol Res 2014, 149185 (2014).

6. Grivennikov, S. I., Greten, F. R. \& Karin, M. Immunity, Inflammation, and Cancer. Ce// 140, 883-899 (2010).

7. McCarthy, P. L. Down-regulation of cytokine action. Baillieres Clin Haematol 7, 153-177 (1994).

8. Braicu, C. et al. A Comprehensive Review on MAPK: A Promising Therapeutic Target in Cancer. Cancers (Basel) 11, 1618 (2019).

9. Dhillon, A. S., Hagan, S., Rath, O. \& Kolch, W. MAP kinase signalling pathways in cancer. Oncogene 26, 3279-3290 (2007).

10. Al-Qura'n, S. Ethnopharmacological survey of wild medicinal plants in Showbak, Jordan. J Ethnopharmacol 123, 45-50 (2009).

11. Elyasiyan, U. et al. Anti-diabetic activity of aerial parts of Sarcopoterium spinosum. BMC Complement Altern Med 17, 356 (2017).

12. Ali-shtayeh, M. saleem, Yaniv, Z. \& Mahajna, J. Ethnobotanical survey in the Palestinian area: A classification of the healing potential of medicinal plants. Journal of ethnopharmacology 73, 221-32 (2000).

13. Yaniv, Z. Ethnobotanical studies of Sarcopoterium spinosum in Israel. Israel Journal of Plant Sciences - ISRAEL J PLANT SCI 55, 111-114 (2007).

14. Said, O., Khalil, K., Fulder, S. \& Azaizeh, H. Ethnopharmacological survey of medicinal herbs in Israel, the Golan Heights and the West Bank region. Journal of ethnopharmacology 83, 251-65 (2003).

15. Hudec, J. et al. In Vitro Cytotoxic Effects of Secondary Metabolites Present in Sarcopoterium Spinosum L. Applied Sciences 11, 5300 (2021).

16. Rozenberg, K., Wollman, A., Ben-Shachar, M., Argaev-Frenkel, L. \& Rosenzweig, T. Antiinflammatory effects of Sarcopoterium spinosum extract. Journal of Ethnopharmacology 249, 112391 (2020).

17. Aburjai, T., Hudaib, M., Tayyem, R., Yousef, M. \& Qishawi, M. Ethnopharmacological survey of medicinal herbs in Jordan, the Ajloun Heights region. J Ethnopharmacol 110, 294-304 (2007).

18. Schmidt, E. V. The role of c-myc in cellular growth control. Oncogene 18, 2988-2996 (1999). 
19. Obaya, A. J., Mateyak, M. K. \& Sedivy, J. M. Mysterious liaisons: the relationship between c-Myc and the cell cycle. Oncogene 18, 2934-2941 (1999).

20. Bretones, G., Delgado, M. D. \& León, J. Myc and cell cycle control. Biochim Biophys Acta 1849, 506-516 (2015).

21. Barnaba, N. \& LaRocque, J. R. Targeting cell cycle regulation via the G2-M checkpoint for synthetic lethality in melanoma. Cell Cycle 20, 1041-1051 (2021).

22. Zhang, Y., Qian, J., Gu, C. \& Yang, Y. Alternative splicing and cancer: a systematic review. Signal Transduction and Targeted Therapy vol. 61-14 (2021).

23. Anczukow, O. \& Krainer, A. R. Splicing-factor alterations in cancers. RNA vol. 22 1285-1301 (2016).

24. Kalev, P. et al. MAT2A Inhibition Blocks the Growth of MTAP-Deleted Cancer Cells by Reducing PRMT5-Dependent mRNA Splicing and Inducing DNA Damage. Cancer Cell 39, 209-224.e11 (2021).

25. Park, J.-S., Davis, R. L. \& Sue, C. M. Mitochondrial Dysfunction in Parkinson's Disease: New Mechanistic Insights and Therapeutic Perspectives. Curr Neurol Neurosci Rep 18, 21 (2018).

26. Prasuhn, J., Davis, R. L. \& Kumar, K. R. Targeting Mitochondrial Impairment in Parkinson's Disease: Challenges and Opportunities. Frontiers in Cell and Developmental Biology 8, 1704 (2021).

27. Kaplan, J. Friedreich's ataxia is a mitochondrial disorder. Proc Natl Acad Sci U S A 96, 1094810949 (1999).

28. Lynch, D. R. \& Farmer, G. Mitochondrial and metabolic dysfunction in Friedreich ataxia: update on pathophysiological relevance and clinical interventions. Neuronal Signaling 5, NS20200093 (2021).

29. Zorova, L. D. et al. Mitochondrial membrane potential. Anal Biochem 552, 50-59 (2018).

30. Liu, W. J. et al. p62 links the autophagy pathway and the ubiqutin-proteasome system upon ubiquitinated protein degradation. Cellular \& Molecular Biology Letters 21, 29 (2016).

31. Marinković, M., Šprung, M., Buljubašić, M. \& Novak, I. Autophagy Modulation in Cancer: Current Knowledge on Action and Therapy. Oxidative Medicine and Cellular Longevity 2018, e8023821 (2018).

32. Chen, C., Turnbull, D. M. \& Reeve, A. K. Mitochondrial Dysfunction in Parkinson's Disease-Cause or Consequence? Biology (Basel) 8, 38 (2019).

33. Wang, Y. et al. Centrosome-associated regulators of the G2/M checkpoint as targets for cancer therapy. Molecular Cancervol. 88 (2009). 
34. Miller, D. M., Thomas, S. D., Islam, A., Muench, D. \& Sedoris, K. c-Myc and cancer metabolism. Clinical Cancer Research vol. 18 5546-5553 (2012).

35. Fabregat, I., Fernando, J., Mainez, J. \& Sancho, P. TGF-beta Signaling in Cancer Treatment IT-Liver View project Hepatocellular carcinoma View project. (2014) doi:10.2174/13816128113199990591.

36. Krishnamurthy, N. \& Kurzrock, R. Targeting the Wnt/beta-catenin pathway in cancer: Update on effectors and inhibitors. Cancer Treatment Reviews vol. 62 50-60 (2018).

37. Bai, X., Yi, M., Jiao, Y., Chu, Q. \& Wu, K. Blocking TGF- $\beta$ Signaling To Enhance The Efficacy Of Immune Checkpoint Inhibitor. Onco Targets Ther 12, 9527-9538 (2019).

38. Krishnamurthy, N. \& Kurzrock, R. Targeting the Wnt/beta-catenin Pathway in Cancer: Update on Effectors and Inhibitors. Cancer Treat Rev 62, 50-60 (2018).

39. Dang, C. V. MYC on the Path to Cancer. Cell 149, 22-35 (2012).

40. Loizzo, M. R. et al. Antiproliferative activities on renal, prostate and melanoma cancer cell lines of Sarcopoterium spinosum aerial parts and its major constituent tormentic acid. Anticancer Agents Med Chem 13, 768-776 (2013).

41. Ramirez, H., Patel, S. B. \& Pastar, I. The Role of TGF $\beta$ Signaling in Wound Epithelialization. Adv Wound Care (New Rochelle) 3, 482-491 (2014).

42. Penn, J. W., Grobbelaar, A. O. \& Rolfe, K. J. The role of the TGF- $\beta$ family in wound healing, burns and scarring: a review. Int J Burns Trauma 2, 18-28 (2012).

43. Wu, C. et al. IFN-y primes macrophage activation by increasing phosphatase and tensin homolog via downregulation of miR-3473b. J Immuno/ 193, 3036-3044 (2014).

44. Hu, X., Chakravarty, S. D. \& Ivashkiv, L. B. Regulation of IFN and TLR Signaling During Macrophage Activation by Opposing Feedforward and Feedback Inhibition Mechanisms. Immunol Rev 226, 41-56 (2008).

45. Welsh, R. M. Natural killer cells and interferon. Crit Rev Immuno/ 5, 55-93 (1984).

46. Müller, L., Aigner, P. \& Stoiber, D. Type I Interferons and Natural Killer Cell Regulation in Cancer. Front Immunol 8, 304 (2017).

47. Mantlo, E., Bukreyeva, N., Maruyama, J., Paessler, S. \& Huang, C. Antiviral activities of type I interferons to SARS-CoV-2 infection. Antiviral Res 179, 104811 (2020).

48. Sainz, B., Mossel, E. C., Peters, C. J. \& Garry, R. F. Interferon-beta and interferon-gamma synergistically inhibit the replication of severe acute respiratory syndrome-associated coronavirus (SARSCoV). Virology 329, 11-17 (2004). 
49. Slomski, A. Trials Test Mushrooms and Herbs as Anti-COVID-19 Agents. JAMA 326, 1997-1999 (2021).

50. Shahzad, F., Anderson, D. \& Najafzadeh, M. The Antiviral, Anti-Inflammatory Effects of Natural Medicinal Herbs and Mushrooms and SARS-CoV-2 Infection. Nutrients 12, 2573 (2020).

51. Lin, L.-T., Hsu, W.-C. \& Lin, C.-C. Antiviral Natural Products and Herbal Medicines. Journal of Traditional and Complementary Medicine 4, 24-35 (2014).

52. Kong, Q. et al. Analysis of the molecular mechanism of Pudilan (PDL) treatment for COVID-19 by network pharmacology tools. Biomed Pharmacother 128, 110316 (2020).

53. Rozenberg, K., Smirin, P., Sampson, S. R. \& Rosenzweig, T. Insulin-sensitizing and insulin-mimetic activities of Sarcopoterium spinosum extract. Journal of Ethnopharmacology 155, 362-372 (2014).

54. Rozenberg, K. \& Rosenzweig, T. Sarcopoterium spinosum extract improved insulin sensitivity in mice models of glucose intolerance and diabetes. PLOS ONE 13, e0196736 (2018).

55. Stolz, A., Ernst, A. \& Dikic, I. Cargo recognition and trafficking in selective autophagy. Nat Cell Biol 16, 495-501 (2014).

56. Bjørkøy, G. et al. Chapter 12 Monitoring Autophagic Degradation of p62/SQSTM1. in Methods in Enzymology vol. 452 181-197 (Academic Press, 2009).

57. Masoudi-Sobhanzadeh, Y., Omidi, Y., Amanlou, M. \& Masoudi-Nejad, A. Drug databases and their contributions to drug repurposing. Genomics vol. 112 1087-1095 (2020).

58. Choi, W. \& Lee, H. Inference of Biomedical Relations among Chemicals, Genes, Diseases, and Symptoms Using Knowledge Representation Learning. IEEE Access 7, 179373-179384 (2019).

59. Hebels, D. G. et al. Evaluation of database-derived pathway development for enabling biomarker discovery for hepatotoxicity. Biomarkers in Medicine vol. 8 185-200 (2014).

60. Rappaport, N. et al. MalaCards: An amalgamated human disease compendium with diverse clinical and genetic annotation and structured search. Nucleic Acids Research 45, D877-D887 (2017).

61. Dafni, A., Yaniv, Z. \& Palevitch, D. Ethnobotanical survey of medicinal plants in northern Israel. Journal of Ethnopharmacology 10, 295-310 (1984).

62. Scudiero, D. A. et al. Evaluation of a Soluble Tetrazolium/Formazan Assay for Cell Growth and Drug Sensitivity in Culture Using Human and Other Tumor Cell Lines. Cancer Res 48, 4827-4833 (1988).

63. Ewing, B., Hillier, L., Wendl, M. C. \& Green, P. Base-calling of automated sequencer traces using phred. I. Accuracy assessment. Genome Res 8, 175-185 (1998). 
64. Babraham Bioinformatics - FastQC A Quality Control tool for High Throughput Sequence Data. https://www.bioinformatics.babraham.ac.uk/projects/fastqc/.

65. HISAT2. HISAT2 http://DaehwanKimLab.github.io/hisat2/.

66. Liao, Y., Smyth, G. K. \& Shi, W. featureCounts: an efficient general purpose program for assigning sequence reads to genomic features. Bioinformatics 30, 923-930 (2014).

67. Robinson, M. D., McCarthy, D. J. \& Smyth, G. K. edgeR: a Bioconductor package for differential expression analysis of digital gene expression data. Bioinformatics 26, 139-140 (2010).

68. Zhang, Z. et al. Novel Data Transformations for RNA-seq Differential Expression Analysis. Sci $\operatorname{Rep}$ 9, 4820 (2019).

69. Ritchie, M. E. et al. limma powers differential expression analyses for RNA-sequencing and microarray studies. Nucleic Acids Res 43, e47 (2015).

70. Szklarczyk, D. et al. The STRING database in 2021: customizable protein-protein networks, and functional characterization of user-uploaded gene/measurement sets. Nucleic Acids Res 49, D605-D612 (2021).

71. Shannon, P. et al. Cytoscape: a software environment for integrated models of biomolecular interaction networks. Genome Res 13, 2498-2504 (2003).

72. Subramanian, A. et al. Gene set enrichment analysis: A knowledge-based approach for interpreting genome-wide expression profiles. PNAS 102, 15545-15550 (2005).

\section{Declarations}

\section{Equal contribution}

Valid Gahramanov, Moria Oz has equal contribution in this work.

\section{Author contributions and acknowledgements}

Experiment: The experiment was conceived, designed, and performed by V. Gahramanov, Moria Oz and Bat Chen. R. Lubin.

Anti-viral effect of SSE extract tested by Tzemach Aouizerat and Jonathan Gorelick.

Data analysis: Data handling and analysis related to transcriptome, designing of pipeline for the sequencing analysis was performed by V. Gahramanov. 
Other contributions: Valuable suggestion in data analysis were provided by M. Salmon Divon. Additionally, Simone Baldan contributed to protein expression level measurement.

Manuscript was prepared by V. Gahramanov, Bat Chen. R. Lubin, M. Sherman

Manuscript reviewing and editing by Mali Salmon-Divon, Tovit Rosenzweig, Jonathan Gorelick, Elyashiv Drori

Manuscript was approved by all co-authors.

\section{Data availability}

The list of genes from transcriptome analysis and biological pathway analysis results with their corresponding raw and processed statistical values are available in the supplement section of this paper (Supplementary data Table S1, S2, S3). All other necessary data is included in the main section of the paper. Codes and pipelines will be made available upon request.

\section{Competing interests}

The authors declare no competing interests.

\section{Supplementary data:}

This article contains supplementary data, provided separately.

\section{Figures}




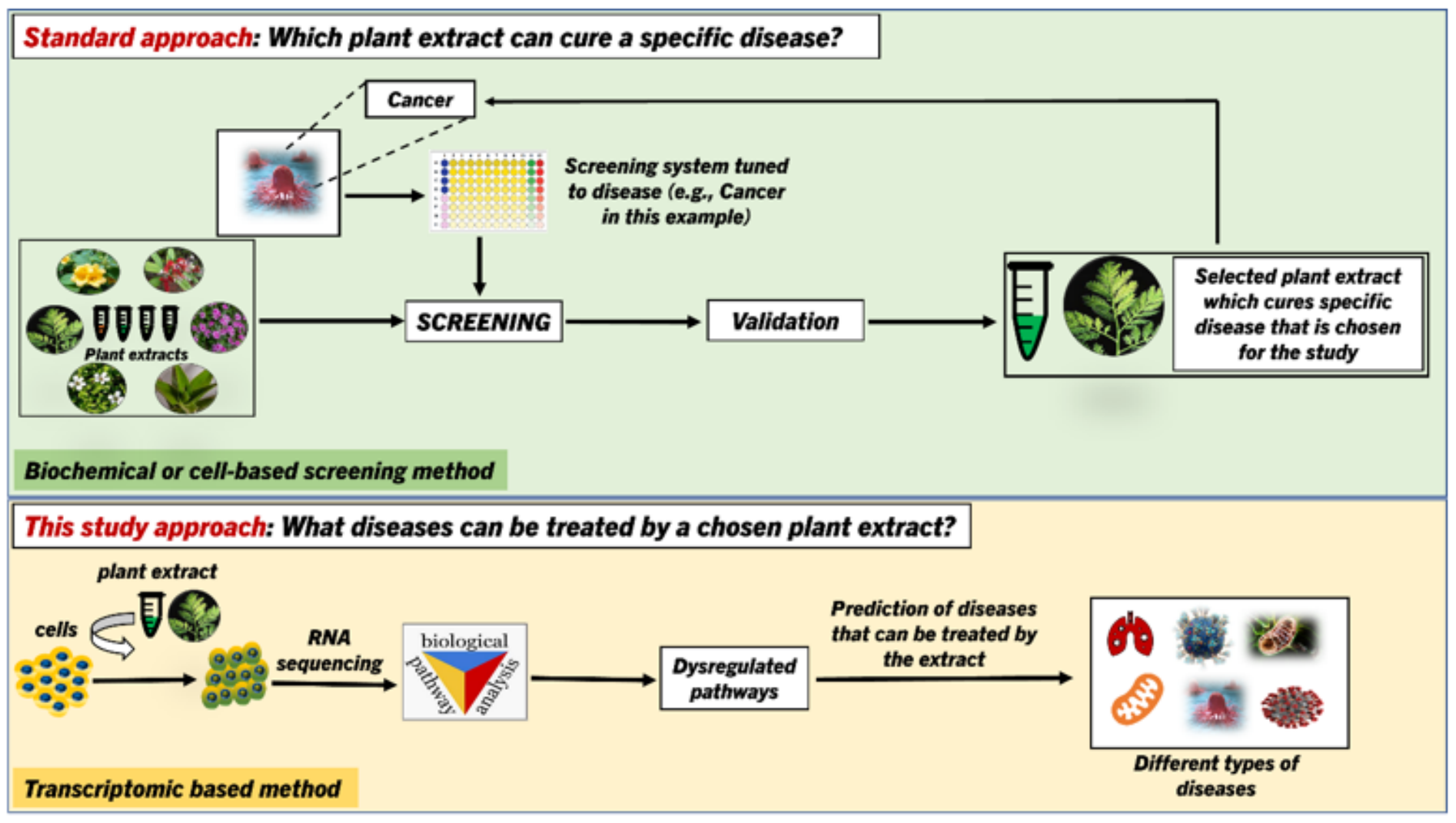

Figure 1

Schematic view of identification of biological activities of the medicinal plant extracts in screening (on the top) and cell transcriptomic analysis (on the bottom)

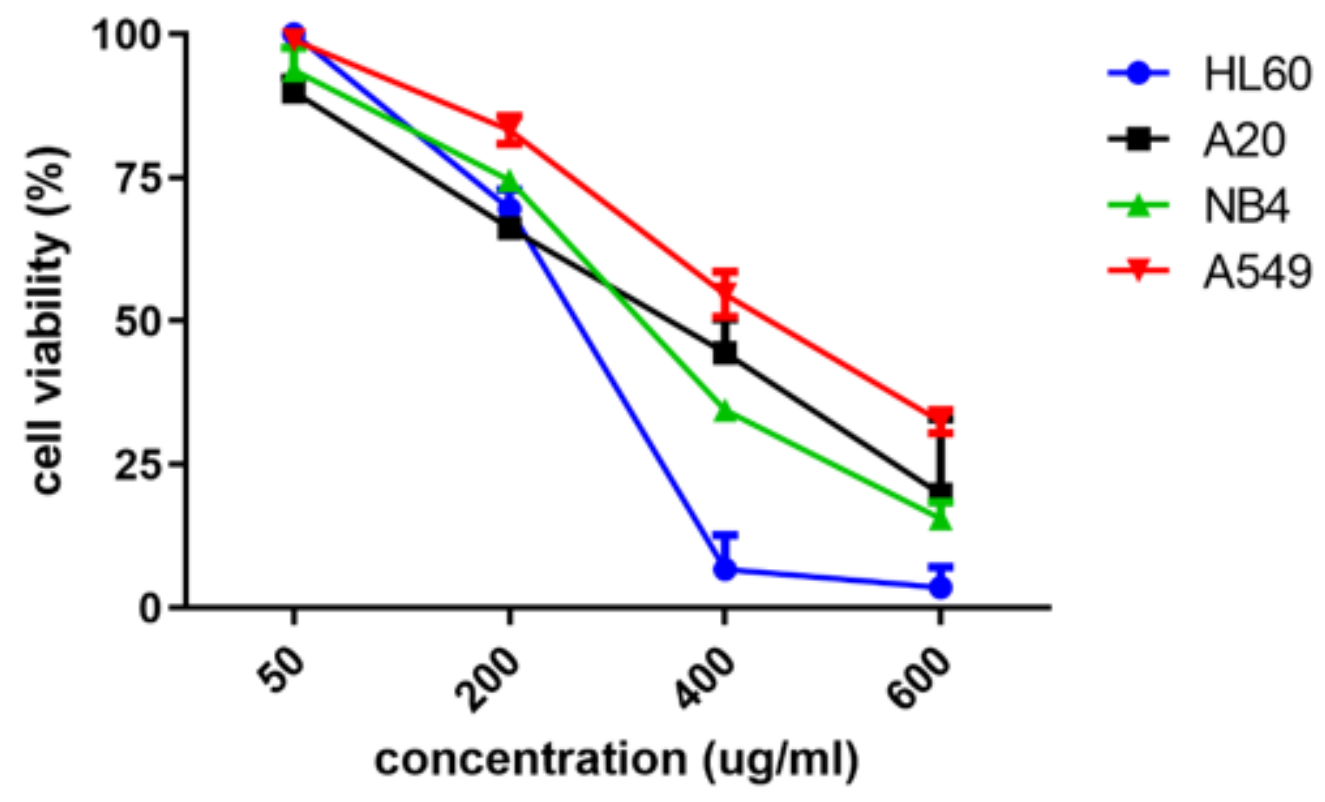


Figure 2

Cytotoxicity assay of Sarcopoterium spinosum with different cell lines. A20 mouse lymphoma (black), HL-60 human promyelocytic leukemia (blue), NB4 cells (green), and A549 human lung cancer cells (red) were incubated with a range of concentrations of SSE for 24h, and XTT assay was performed.

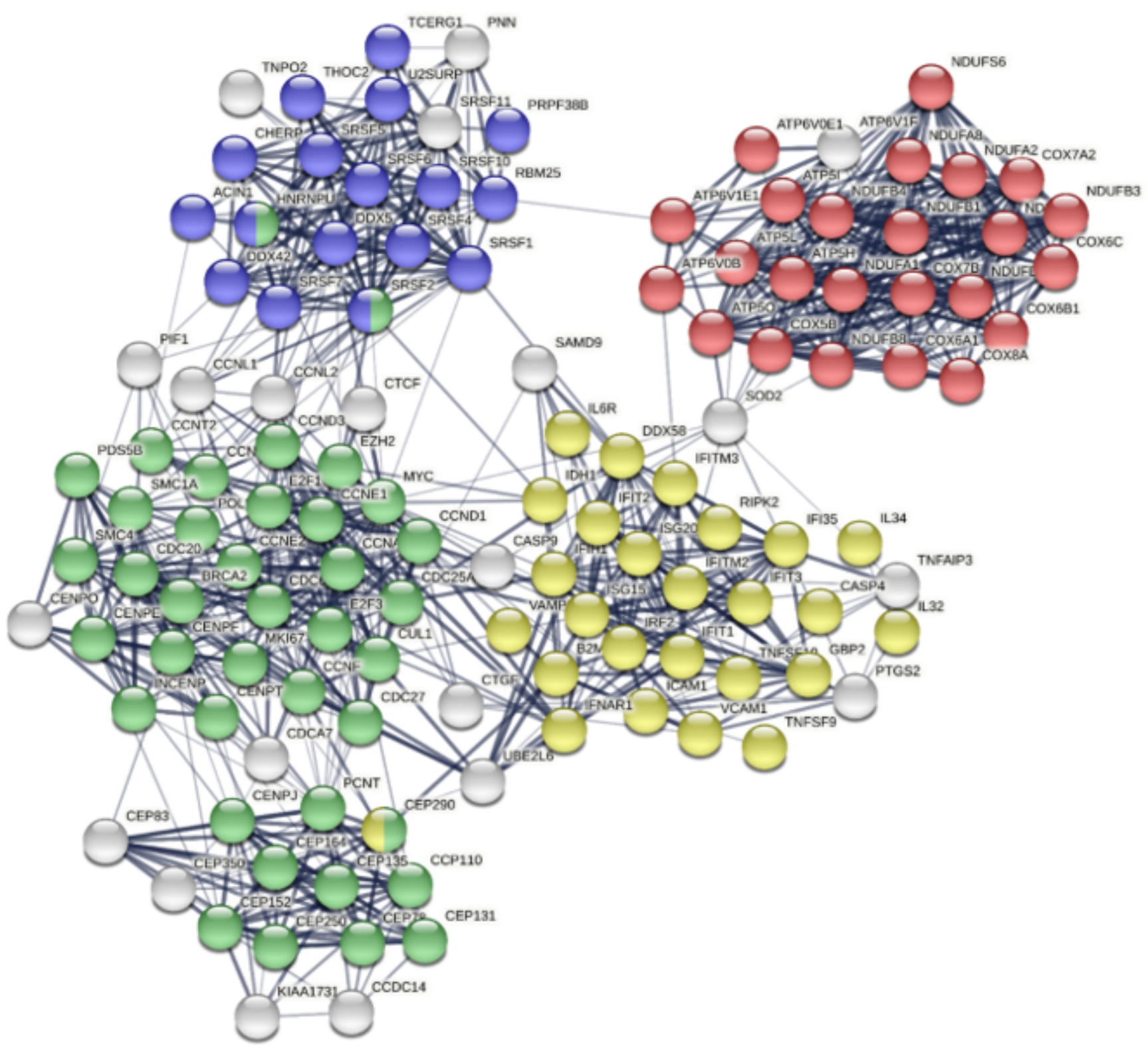

Spliceosome Pathway Oxidative-Phosphorylation Cell Cycle Immune response

\section{Figure 3}


RNAseq-based protein-protein interaction networks of hub genes obtained from the STRING Database (interaction score > 0.9). (Isolated protein nodes were not depicted in Figure). The Intensity of nodes between genes represents the strength of the nodes and the interaction between proteins.
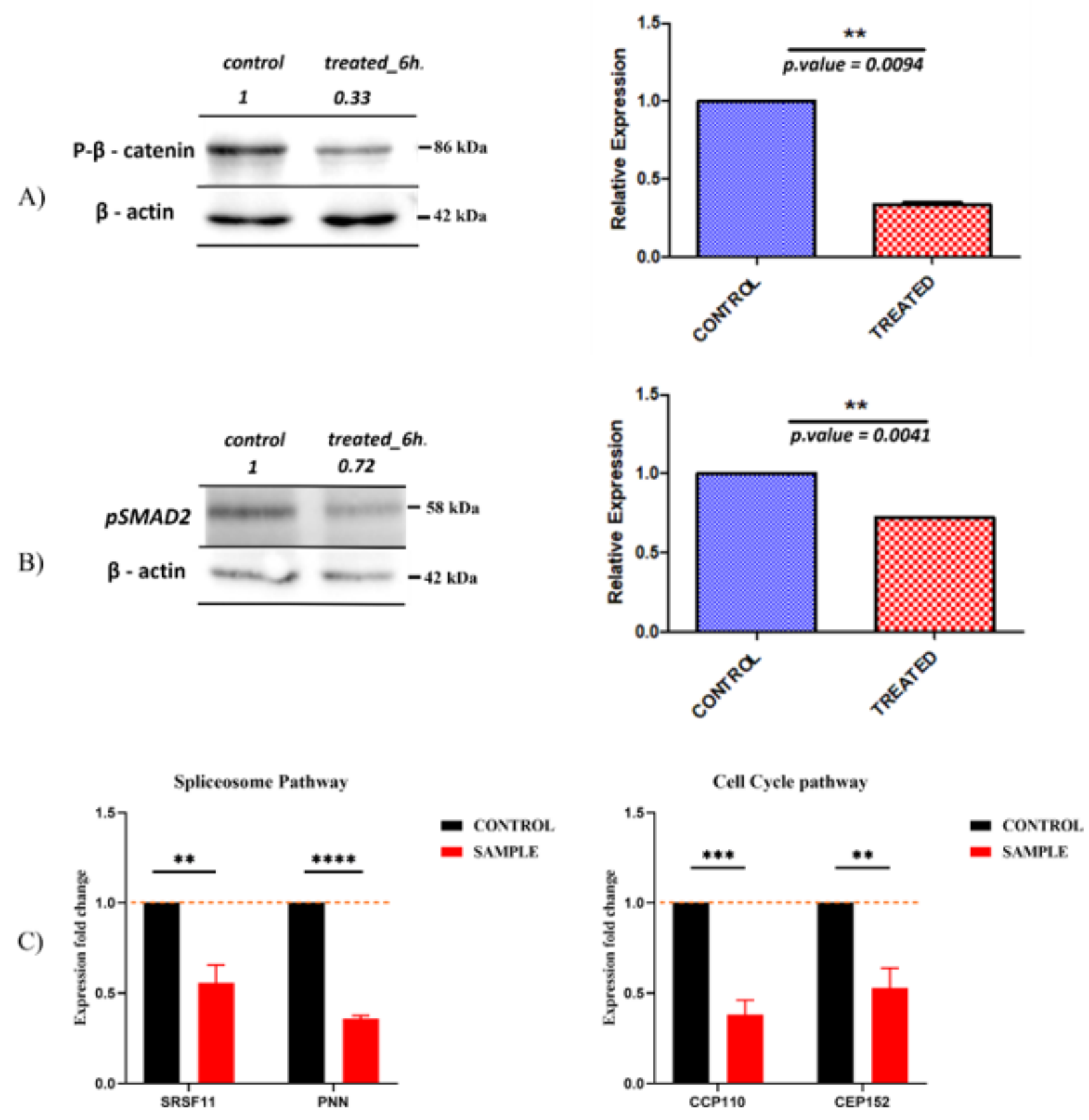

Figure 4

Anti-cancer effects of the SSE extract. Effects of extract on WNT/Beta-catenin and TGF-beta signaling pathways. A549 cells were incubated with the extract for 6 hours and levels of $\beta$-catenin and TGF-beta were assessed by immunoblotting with the corresponding antibodies. A) Levels of $\beta$-catenin. B) Level of SMAD2. C) Real-Time PCR measurement of cancer-related pathways` genes. On the left, Spliceosome 
genes (SRSF11 and PNN) and on the right genes belong to the Cell cycle pathway described (CCP110 and CEP152). Results are representative of three biological replicates $(n=3) .{ }^{*}, P<0.05 ; \star \star, P<0.01 ; * \star \star, P<0.005$; $\star \star \star \star, ~ P<0.001$ (treated vs. control).
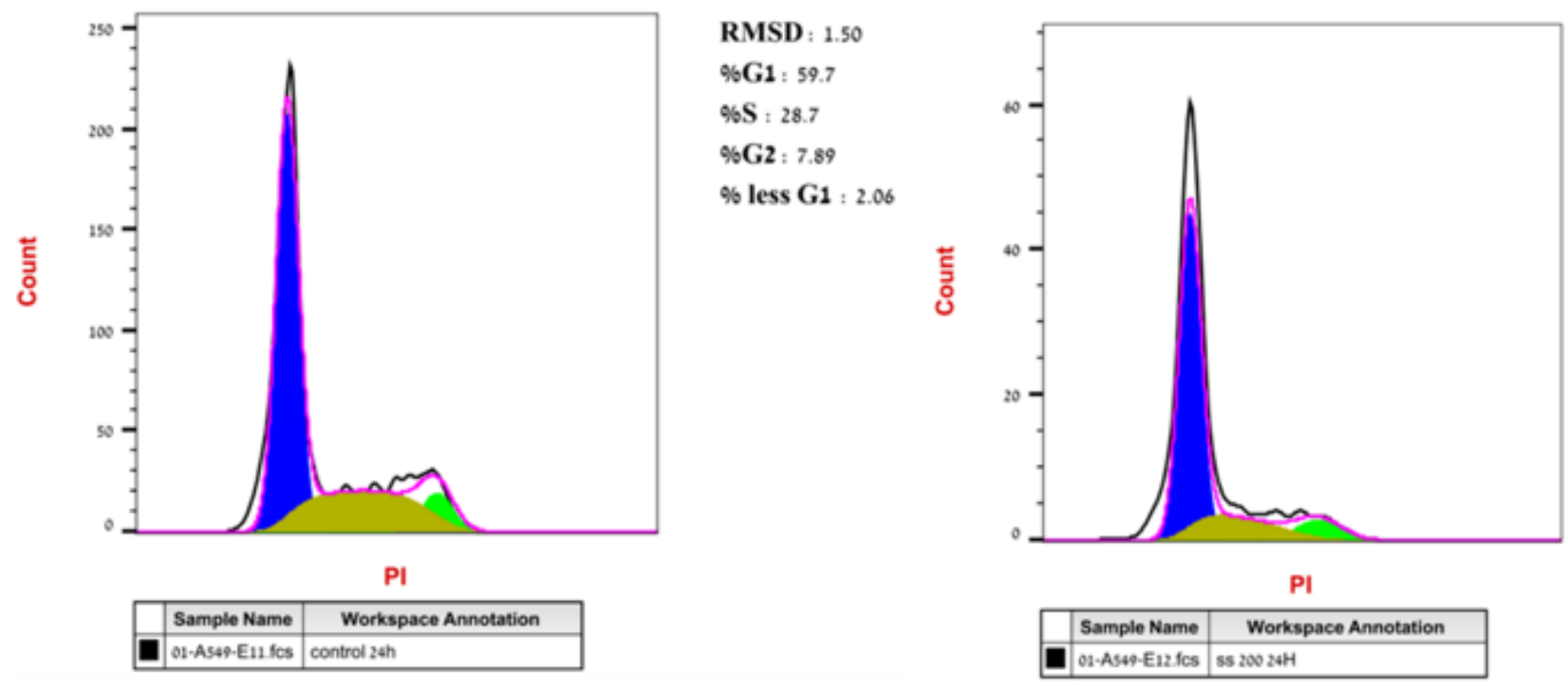

RMSD : 0.37

$\%$ G1 : 67.8

$\% \mathbf{S}: 18.5$

$\% \mathrm{G2}: 8.85$

$\%$ less G1: 3.46

PI

\begin{tabular}{|l|r|r|}
\hline & Sample Name & Workspace Annotation \\
\hline $\mathbf{0}$ & $01-A 549-E 12$ fes & ss $2002 \mathrm{zH}$ \\
\hline
\end{tabular}

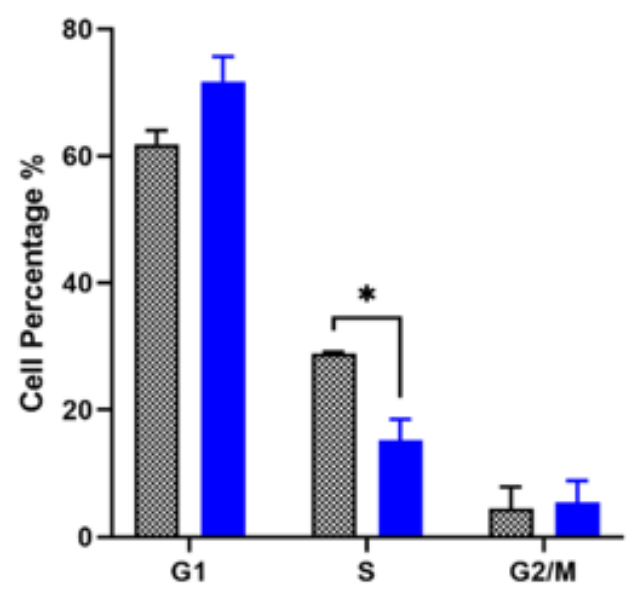

CONTROL

- TREATED

Figure 5

Cell cycle analysis. Flow Cytometry analysis of non-treated (on the left) and extract-treated (for 24 hours) (on the right) A549 lung cancer cells. The Bar graph below shows the quantitative analysis of the flow cytometry experiments described above $(n=3)$. Data are presented as mean \pm S.D. *, $P<0.05$ 
A)

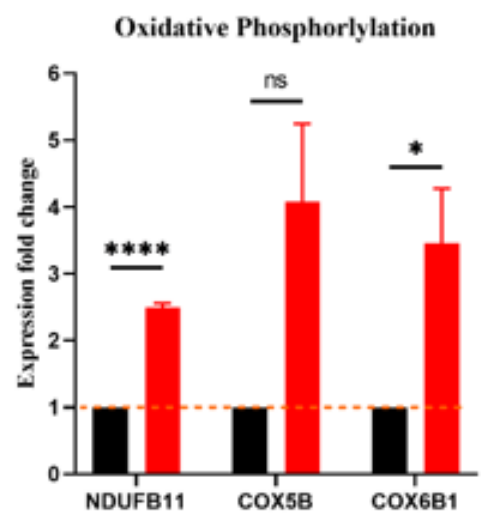

- CONTROL

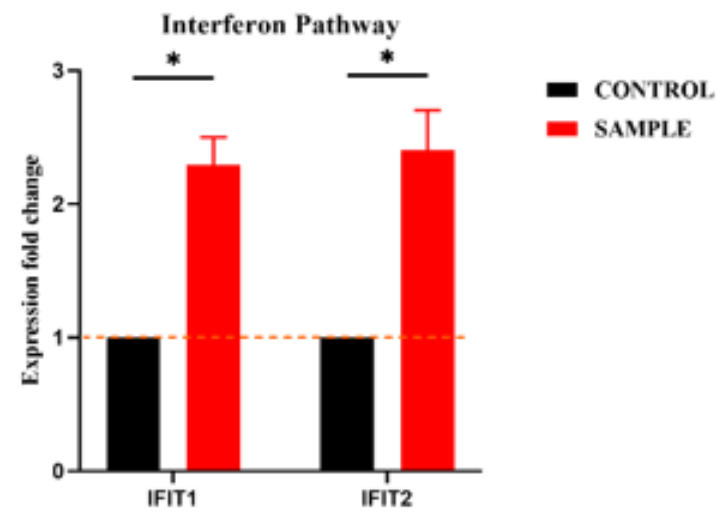

B)
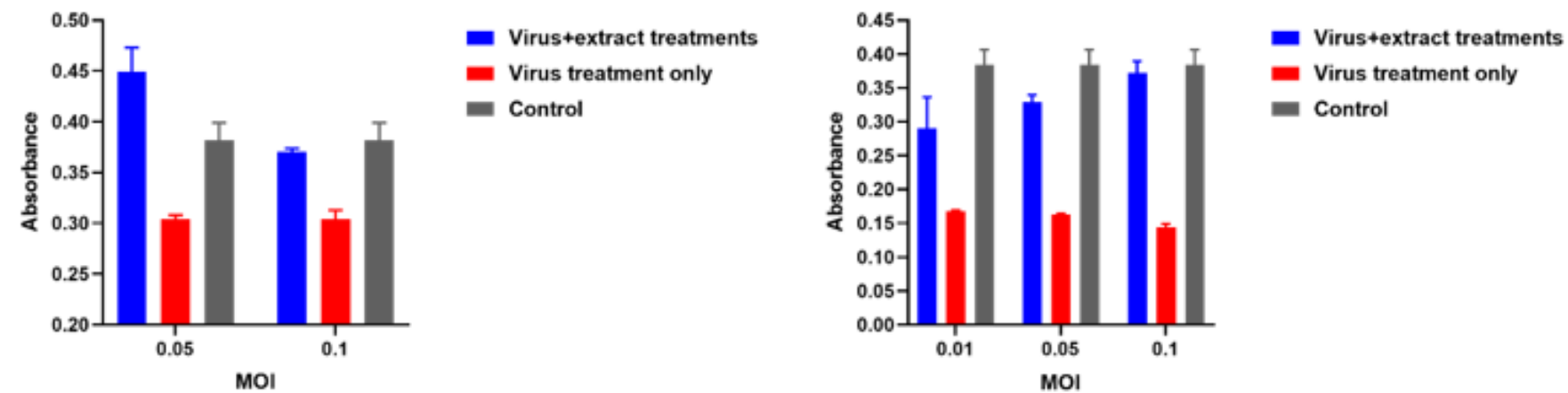

Figure 6

Sarcopoterium spinosum extract activates the anti-viral response. A) Real-Time PCR measurement of mitochondrial (NDUFB11, COX5B, COX6B1) and -interferon-induced genes (IFIT1, IFIT2). *, P<0.05; **, $\mathrm{P}<0.01 ; * \star \star, P<0.005 ; * \star \star \star, P<0.001$ (treated (sample) vs. control). B) The extract protects from the SARSCoV-2 infection. Cells were pretreated with extract for 4 hours, then SARS-CoV-2 virus was added to the cells, cell viability was measured by the MTT assay after 48 hours. On the right viability of VER06 cells, on the left viability of A549 cells have been described. Black - untreated control, Red -Virus treatment only, Blue- virus + extract treatments. 
A)
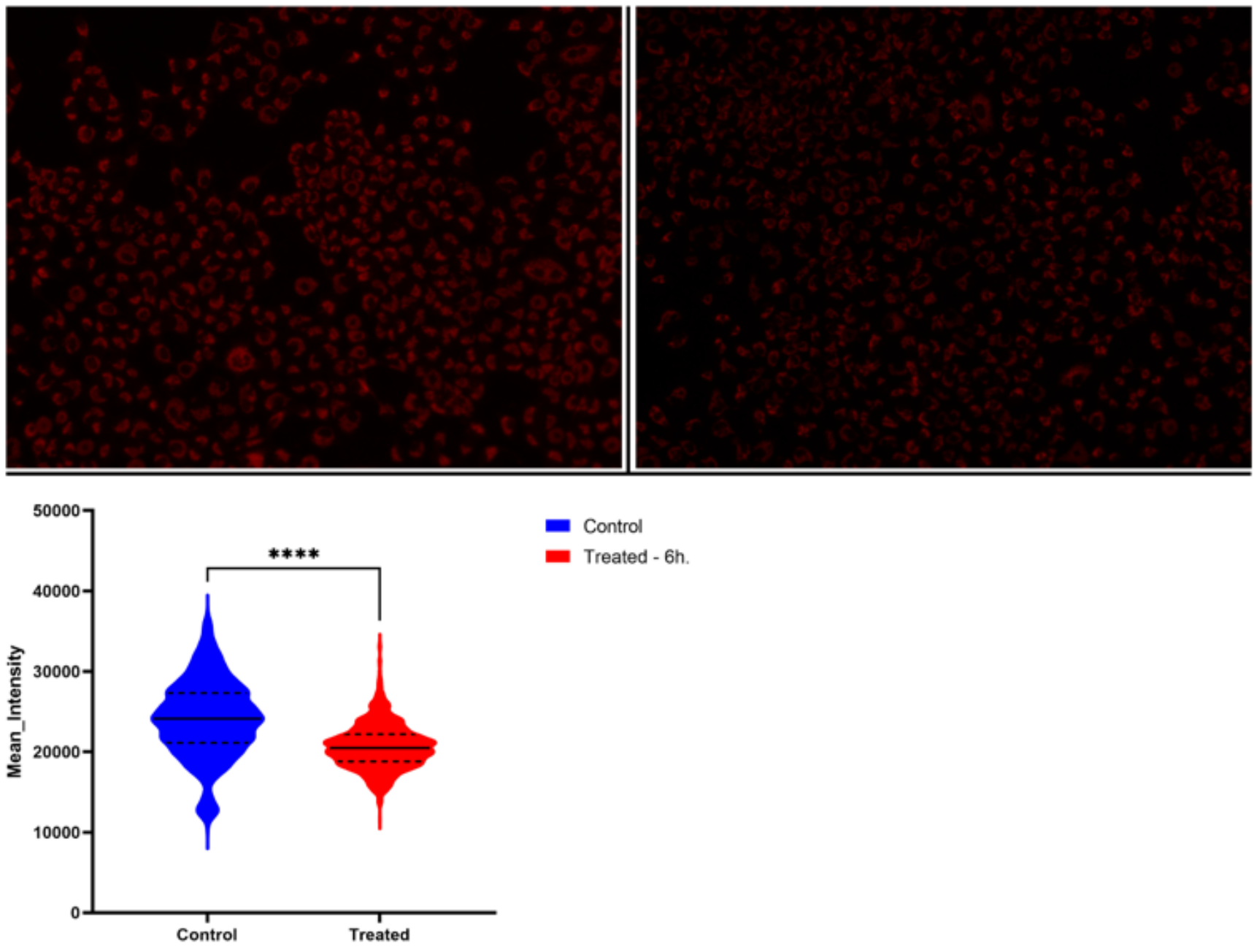

- Control

- Treated - $6 \mathrm{~h}$.

B)

\section{Figure 7}

Measurement of mitochondrial content in A549 cells. A549 cells were treated with SSE $(200 \mu \mathrm{g} / \mathrm{ml})$ for 6 h. Fluorescence intensities of Mito-Tracker Red were quantified. Treatment with SSE reduces the number of mitochondria in cells. A). Representative immunofluorescence images. B). Violin plot demonstrates the difference in mitochondrial content between untreated (blue) and treated (red) samples. On the Y-axis Mean Intensity of the mitochondrial mass of the cells has been shown. Low intensity indicates fewer mitochondria inside the cells. ${ }^{\star} * \star \star, ~ P<0.001$ 
A)

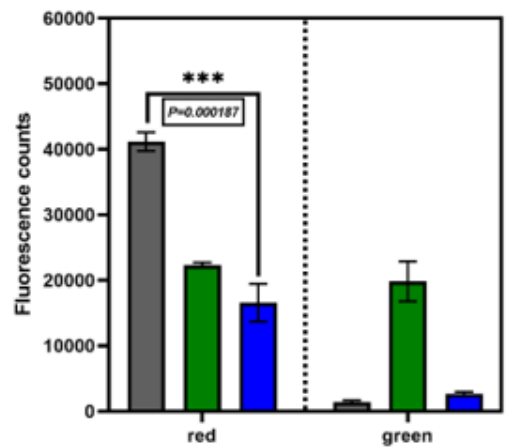

$\square$ Control

ㅁ FCCP

6h treatment
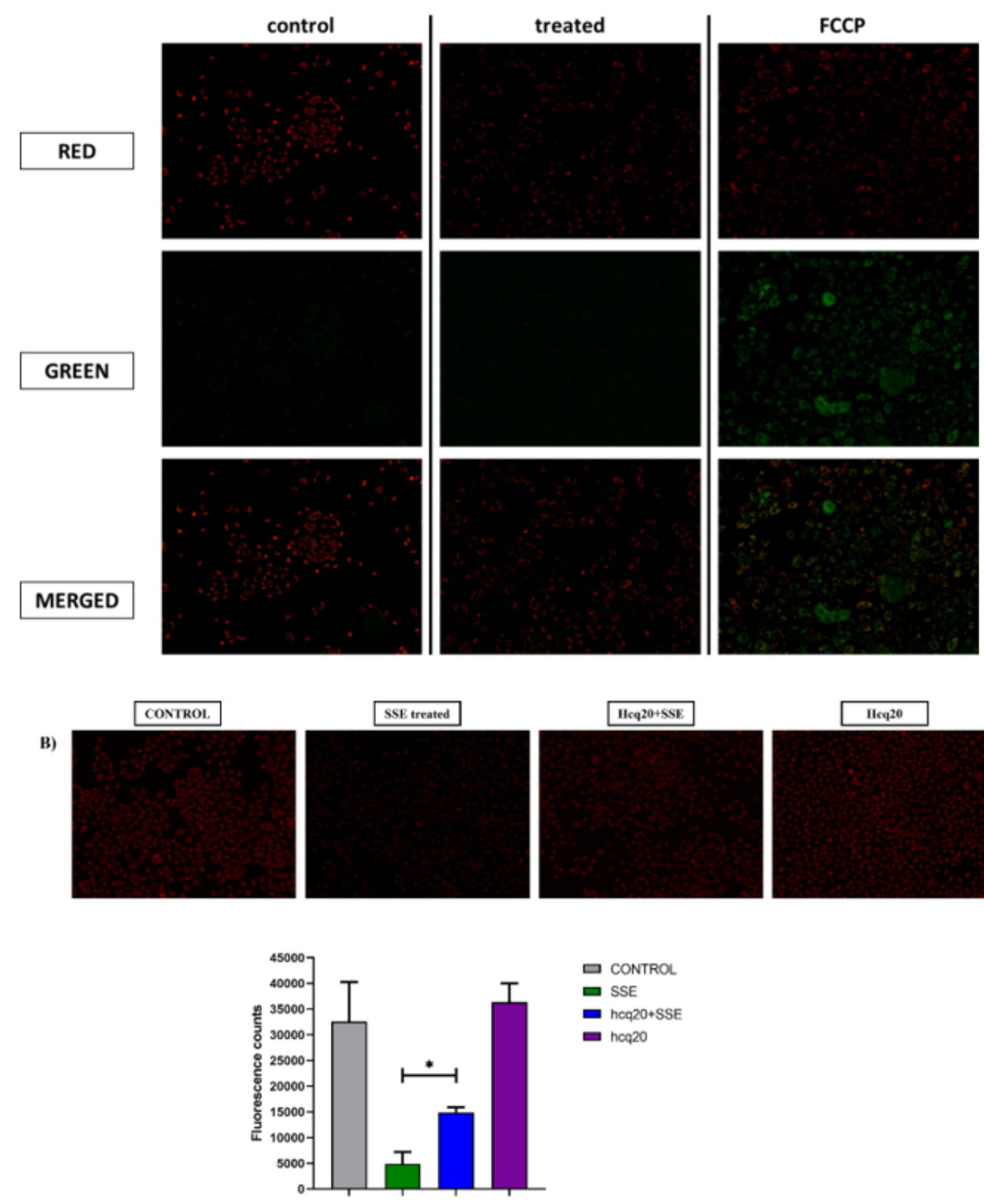

Figure 8

A) Mitochondrial membrane potential assay. A549 cells were treated with $200 \mu \mathrm{g} / \mathrm{mL}$ extract for $6 \mathrm{~h}$ and stained with JC-1. Changes in mitochondrial membrane potential were detected using a JC-1 assay kit containing the cationic dye, which undergoes a readily detectable shift from red to green with decreases in membrane potential. The left panel of the bar graph describes a degradation of mitochondria after treatment with the extract. On the right panel, the level of damaging of the membrane potential of 
mitochondria after administration of extract was shown. FCCP (mitochondrial oxidative phosphorylation uncoupler) was used as a positive control. Microscopy images demonstrate the number of mitochondria inside the cells in red, unhealthy mitochondria in green in A549 cells before and after exposure to SSE extract. B) Mitochondrial autophagic degradation assay. Representative immunofluorescence images using a confocal microscope. A549 were treated with $200 \mu \mathrm{g} / \mathrm{mL}$ extract or with autophagy inhibitor hcq (blocker of the lysosomal $\mathrm{H}^{+}$-ATPases hydroxychloroquine) with or without SSE administration for $6 \mathrm{~h}$ and stained with JC-1. The bar graph indicates the statistical difference in the mitochondrial content of A549 cells. Imaging results are representative of three biological replicates $(n=3)$. ${ }^{\star \star \star}, P<0.005,{ }^{*}, P<0.05$.

A)
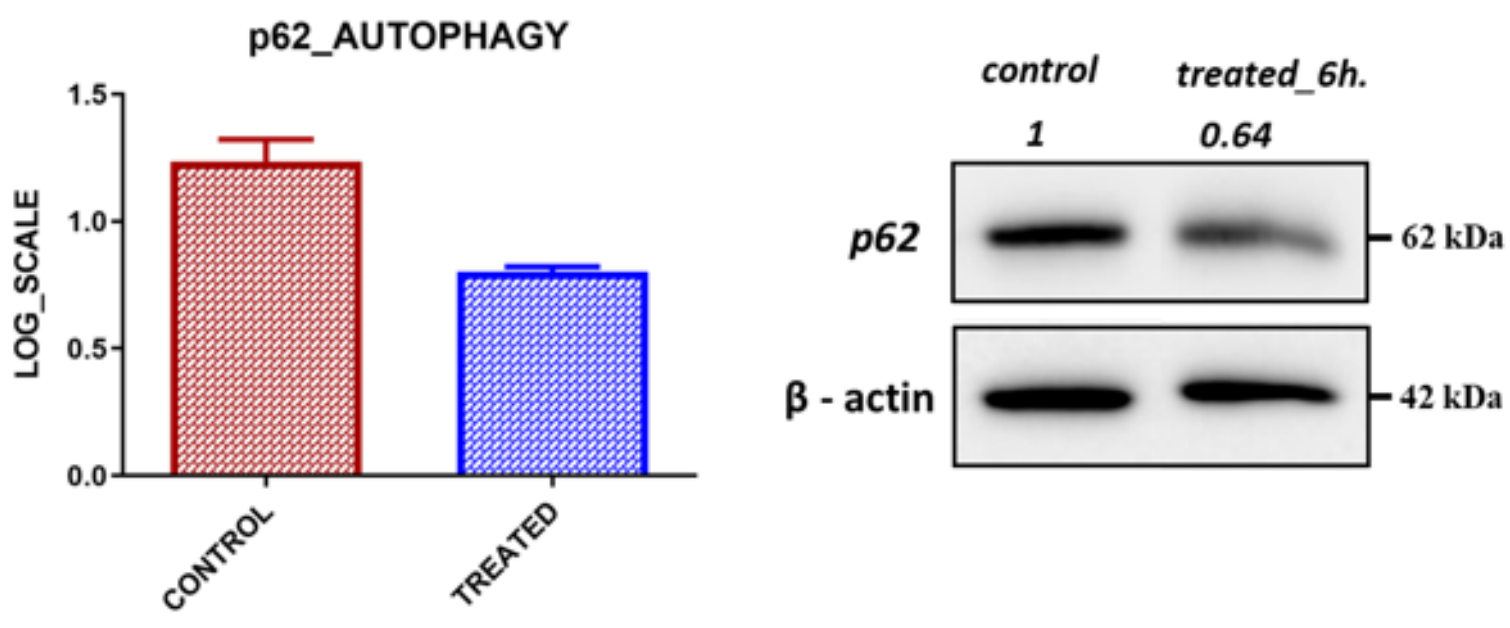

B)

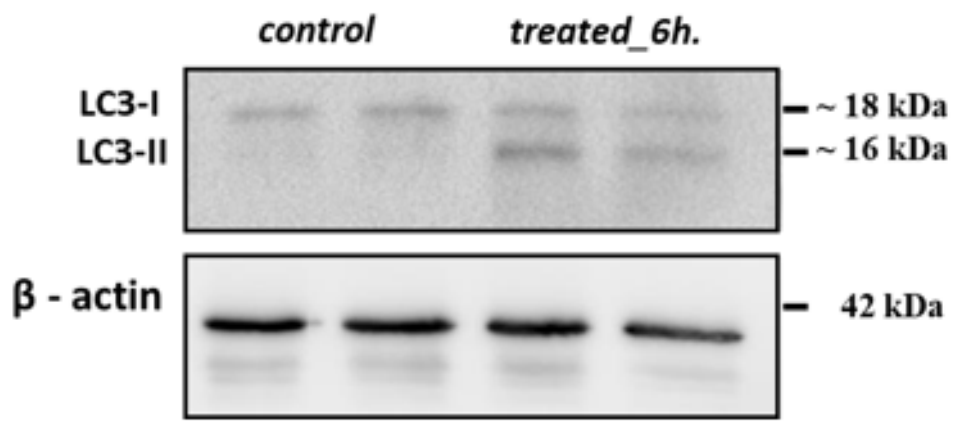

Figure 9

Effect of autophagy on p62 and LC3A/B protein level. A) A decrease of the p62 protein level after treatment with the plant extract. B) Increased level of LC3A/B following treatment with the extract. Cells were either treated or untreated with the extract for 6 hours. 


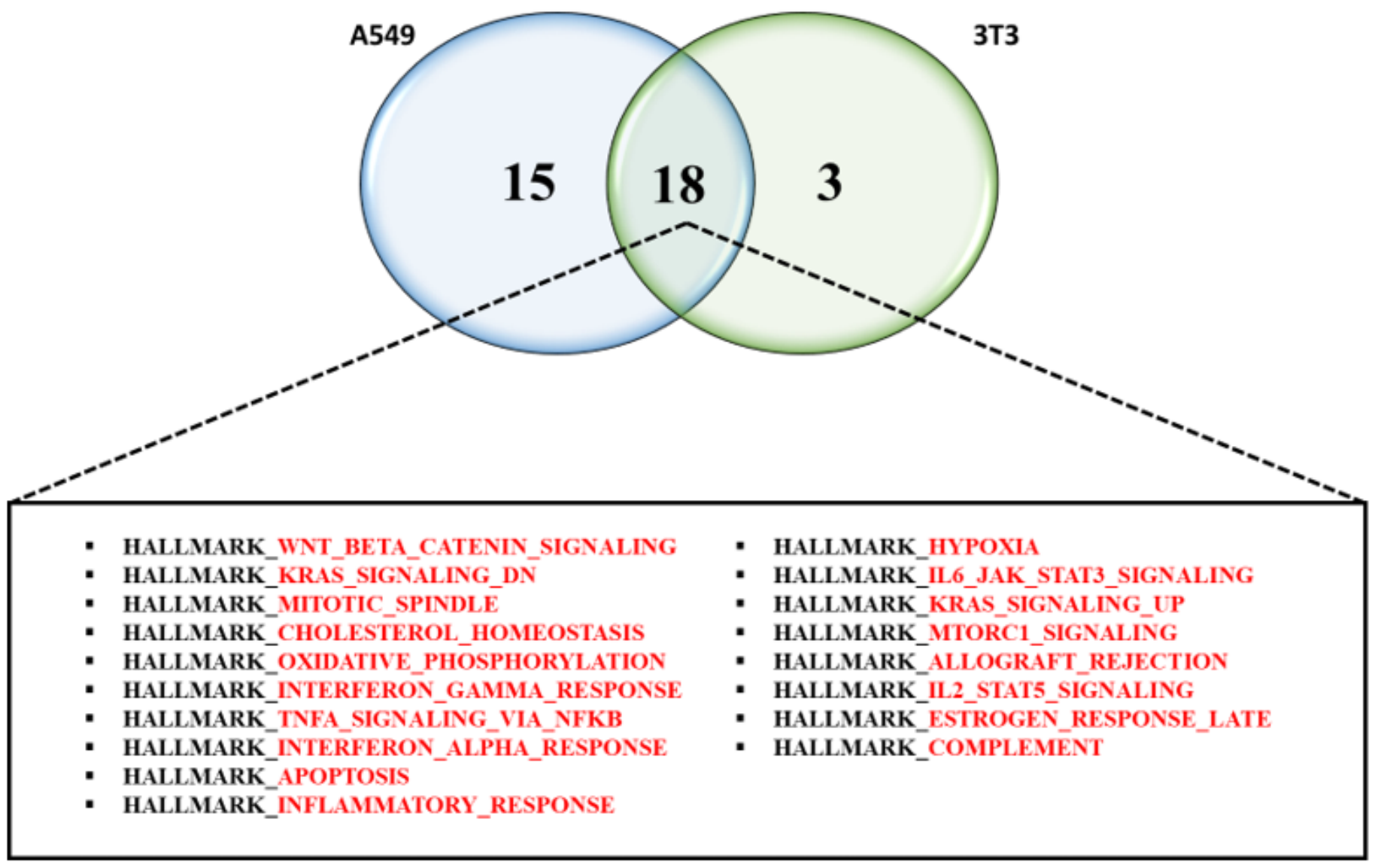

Figure 10

Comparative Gene Set Enrichment Analysis (GSEA) of extract effect on lung (A549) and Mouse Adipocyte (3T3) cell lines. In the middle, the number of common pathways that have been found in both cell lines after extract treatment has been described.

\section{Supplementary Files}

This is a list of supplementary files associated with this preprint. Click to download.

- NewSupplementaryfigureslegends.pdf

- SupplementaryTableS1A549ssvscontrol.xlsx

- SupplementaryTableS2GSEAPATHWAYSSS.xIsx

- SupplementaryTableS3GSEAPATHWAYSMA.xIsx 